Research Journal of Agronomy 4 (2): 24-30, 2010

ISSN: $1815-9354$

(C) Medwell Journals, 2010

\title{
Effects of Salinity on Seedling Biomass Production and Relative Water Content of Twenty Sorghum (Sorghum biolor L. Moench) Accessions
}

\author{
Kinfemichael Geressu Asfaw \\ Department of Biology, College of Natural and Computational Sciences (CNCS), \\ Mekelle University (MU), P.O. Box 3112, Ethiopia
}

\begin{abstract}
Salinity is a continuing problem in the arid and semi-arid tracts of the world. It could be alleviated using irrigation management and/or crop management. However, the former approach is outdated and very expensive. Nevertheless, the latter is economical as well as efficient and it enables to produce salt tolerant crop lines. But prior to that there is a need to confirm the presence of genetically based variation for salt tolerance among different species or varieties of a particular crop at different growth stages. Thus, twenty lowland sorghum (Sorghum bicolor L. Moench.) accessions were tested during early seedling biomass production at $2,4,8$ and $16 \mathrm{dS} \mathrm{m}^{-1}$ salinity levels. Distilled water $\left(0 \mathrm{dS} \mathrm{m}^{-1}\right)$ was used as a control. Data analysis was carried out using jmp5 statistical software (version 5.0). Seedling Shoot Fresh Weight (SFW), seedling Shoot Dry Weight (SDW), seedling Root Fresh Weight (RFW) and seedling Root Dry Weight (RDW) were measured. The two ways ANOVA for accessions found statistically insignificant with respect to most parameters recorded $(p>0.05)$ but it was significant with respect to RFW $(p<0.001$ ). On the other hand, the two ways ANOVA for treatments displayed statistical significance for all parameters at $\mathrm{p}<0.0001$ except at $\mathrm{p}<0.01$ for RFW. However, it was insignificant for accession*treatment interaction ( $\mathrm{p}>0.05$ ). Accessions such as $235461,69239,223550$, 69029 and 23403 were found to be salt tolerant during seedling biomass production and in Relative Water Content (RWC). On the other hand, accessions 22885, 233247, 237264, 237265 and 237267 were found to be salt sensitive during seedling biomass production and in RWC. The rest sorghum accessions were intermediate in their salt tolerance. The study affirmed the presence of broad intraspecific genetic variation in sorghum accessions for salt stress with respect to their early biomass production and Relative Water Content (RWC).
\end{abstract}

Key words: Accessions, $\mathrm{NaCl}$, Relative Water Content (RWC), salinity, seedling biomass, sorghum

\section{INTRODUCTION}

Salt-affected soils are distributed throughout the world and no continent is free from the problem (Brady and Weil, 2002). Salt-affected soils are serious threats to crop production in the arid and semi-arid tracts of the world (Verma and Yadava, 1986). Globally, a total land area of 831 million ha is salt-affected. African countries like Kenya ( $8.2 \mathrm{Mha})$, Nigeria (5.6 Mha), Sudan (4.8 Mha), Tunisia (1.8 Mha), Tanzania (1.7 Mha) and Ghana (0.79 Mha) are salt-affected to various degrees (FAO, 2005). In Ethiopia, salt-affected soils are prevalent in the Rift valley and the lowlands.

The Awash valley in general and the lower plains in particular are dominated by salt-affected soils (Gebreselassie, 1993). For example, soil salinity has caused a significant abandonment of banana plantation and showed a dramatic spread to the adjacent cotton plantation of Melka Sadi Farm (Abegaz, 1995). Furthermore, recent studies also reported that of the entire Abaya state farm, $30 \%$ has already been salt-affected
(Tsige et al., 2000). This problem is expected to be severe in years to come. This is because under the prevailing situation of the country, there is a tendency to introduce and implement large-scale irrigation agriculture so as to meet the demands of the ever-increasing human population by elevating productivity (Mamo et al., 1996). In the absence of efficient ways of irrigated water management, salt build up is an inevitable problem.

The possible solution is either using physical practice (irrigation frequency and leaching, irrigation methods, cyclic use of multiqualtiy waters, fertility management and amendments) or biological practice (attainment of salt tolerant species and cultivars through biological approaches) (Gupta and Minhas, 1993). Since physical practice (irrigation management) is not economically feasible (El-Khashab et al., 1997), there is a need to concentrate on the biological approach or crop management (Ashraf and McNeilly, 1988).

Nevertheless to proceed with this approach, affirming the presence of genetically based variation for salt tolerance in a particular crop is a prerequisite (Marler and 
Mickelbart, 1993). This could be done at different crop growth stages such as crop establishment (germination, emergence and seedling growth). There are reasonably adequate information on the effects of salinity on crops germination and emergence (Maas, 1986).

However, there is only a little information on the impacts of salinity on crops biomass production during seedling growth (Katerji et al., 1994). Therefore, this research attempted to investigate the response of twenty sorghum (Sorghum bicolor, L. Moench) accessions for salt stress with respect to seedling biomass production and Relative Water Content (RWC). The reason for selecting sorghum for the research are being a dual crop grown for both grain and forage, native to tropical regions (Azhar and McNeilly, 1987) and its resistance to environmental fluctuations and drought (Marambe and Ando, 1995). Moreover, previous reports on salt tolerance of sorghum are relatively few.

\section{MATERIALS AND METHODS}

Germination experiment: Seeds of twenty lowland growing sorghum (Sorghum bicolor L. Moench) accessions were obtained from the Institute of Biodiversity Conservation (IBC), Ethiopia. The specific sorghum genotypes used in the research were accessions $69029,69086,69096,69117,69239,69309,223247,223550$, $228851,231190,234071,234093,235461,237264,237265$, $237266,237267,237311,239211$ and 239237.

They are adapted to altitudes ranging between $1400-$ $1550 \mathrm{~m}$ a.s.1. The $\mathrm{NaCl}$ concentrations used were 2, 4,8 and $16 \mathrm{dS} \mathrm{m}^{-1}$. These salinity levels were obtained by dissolving $1.12,2.10$ and 4.95 and $9.9 \mathrm{~g} \mathrm{NaCl}$ in $1 \mathrm{~L}$ distilled water, respectively. Distilled water $\left(0 \mathrm{dS} \mathrm{m}^{-1}\right)$ was used as a control.

Germination experiment was conducted in a laboratory at room temperature following the procedures used by Mamo et al. (1996). Petri dishes with a diameter of $10 \mathrm{~cm}$ lined with Whatman No. 3 filter paper were supplied with $10 \mathrm{~mL}$ of each treatment solution and the control. Following this, twelve uniform seeds of each sorghum accession were placed on each petri dish and the petri dishes were arranged in a Randomized Complete Block Design (RCBD) with four replications.

Eventually, the petri dishes were covered with a polyethylene sheet to avoid the loss of moisture through evaporation. Treatment application continued every other day and germination count was started after $48 \mathrm{~h}$ of sowing and continued until the 14th day. The seed was considered to have germinated when both the plumule and radicle had emerged $\geq 0.5 \mathrm{~cm}$. After the 14 days, seedling shoot and root fresh weights were recorded and finally oven dried at $70^{\circ} \mathrm{C}$ for $48 \mathrm{~h}$ and the seedling dry weight was measured using sensitive balance (Shalaby et al., 1993).

$$
\begin{aligned}
& \text { Relativeseedling water content was calculated }= \\
& \frac{(\text { Fresh weight }- \text { Dryweight })}{\text { Fresh weight }} \times 100
\end{aligned}
$$

Statistical analysis: Data analysis was carried out by JMP5 (version 5.0) statistical software where two ways Analysis of Variance (ANOVA) and correlation analysis were done. Since all accessions were quite salt-sensitive at $16 \mathrm{dS} \mathrm{m}^{-1}$ with regard to SFW, RFW, SDW and RDW, the incomplete information obtained from this salinity level have not been included in data analysis.

\section{RESULTS AND DISCUSSION}

Seedling Shoot Fresh Weight (SFW): The two ways ANOVA for accessions and treatment*accession interaction was insignificant ( $p>0.05)$. However, it was statistically significant for treatments $(\mathrm{p}<0.0001)$. Seedling Shoot Fresh Weight (SFW) was facilitated at $2 \mathrm{dS} \mathrm{m}^{-1}$ in accessions 228851, 237266, 223247, 234093, 235461 and 69239 as compared to the control. Accessions 239211, $237266,223247,234071,231190,237264,69117$ and 69096 were more salt-affected but accessions 237311, 239237 , $228851,223550,234093,235461,69239,69086$ and 69029 were least salt-affected at both 4 and $8 \mathrm{dS} \mathrm{m}^{-1}$ salt concentrations compared to the control (Fig. 1).

Seedling Root Fresh Weight (RFW): The two ways ANOVA for accession*treatment interaction was insignificant $(p>0.05)$ however, it was significant for accessions $(p<0.001)$ and also for treatments $(p<0.01)$. Seedling Root Fresh Weight (RFW) was enhanced at $2 \mathrm{dS} \mathrm{m}^{-1}$ in accessions 223247 and 69309 as compared to the control. Nevertheless, this parameter decreased at 4 and $8 \mathrm{dS} \mathrm{m}^{-1}$ salinity levels in all accessions but the effect was pronounced at $8 \mathrm{dS} \mathrm{m}^{-1}$. Accessions 237311, $237267,237265,228851,234093$ and 69309 were most saltaffected but accessions 239211, 239237, 237266, 223550, 234093, 235461, 237264, 69117, 69239, 69096 and 69029 were found to be least salt-affected at $8 \mathrm{dS} \mathrm{m}^{-1}$ in comparison with the control.

Seedling Shoot Dry Weight (SDW): The two ways ANOVA showed statistical significance for treatment $(\mathrm{p}<0.0001)$ but was insignificant for both accession and treatment*accession interaction $(\mathrm{p}>0.05)$. Seedling Shoot Dry Weight (SDW) was enhanced in accessions 237311, $223550,234093,235461,69239,69309$ and 69029 at $2 \mathrm{dS} \mathrm{m}^{-1}$ 


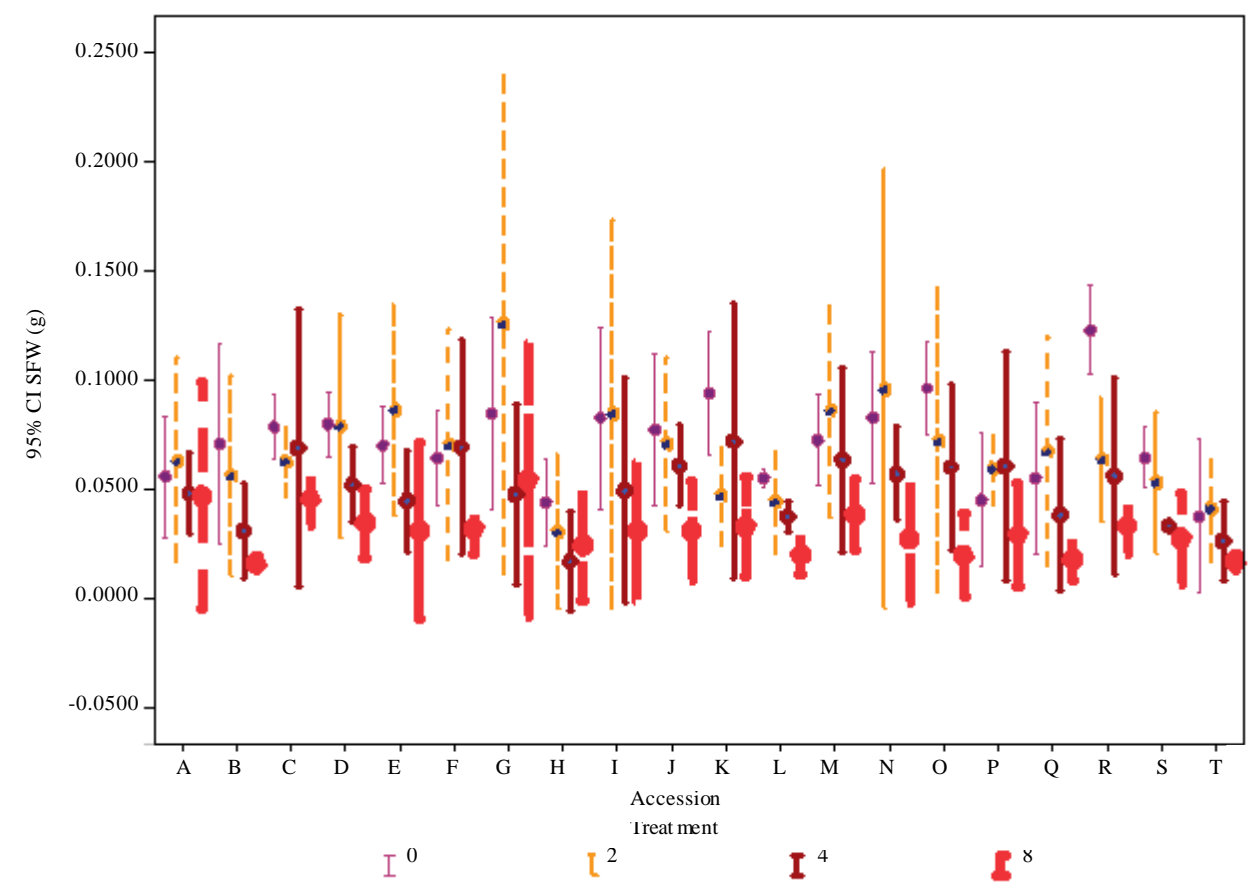

Fig. 1: Effects of different salinity levels $\left(0,2,4\right.$ and $\left.8 \mathrm{dS} \mathrm{m}^{-1}\right)$ on seedling Shoot Fresh Weight (SFW) of Sorghum bicolor $\mathrm{L}$. Moench accessions $(\mathrm{g})(\mathrm{A}=237311, \mathrm{~B}=239211, \mathrm{C}=239237, \mathrm{D}=237267, \mathrm{E}=237266, \mathrm{~F}=237265, \mathrm{G}=$ $228851, \mathrm{H}=223550, \mathrm{I}=223247, \mathrm{~J}=234071, \mathrm{~K}=231190, \mathrm{~L}=234093, \mathrm{M}=235461, \mathrm{~N}=237264, \mathrm{O}=69117, \mathrm{P}=69239$, $\mathrm{Q}=69309, \mathrm{R}=69096, \mathrm{~S}=69086$ and $\mathrm{T}=69029$ )

as compared to the control. Nevertheless, except these accessions, every salinity level decreased SDW but it was more profound at $8 \mathrm{dS} \mathrm{m}^{-1}$. Accessions 239211, 237267, $239237,237265,228851,223247,231190$ and 237264 were most salt-affected however, accessions 237311, 223550, 234093, 235461 and 69029 were least salt-affected at $8 \mathrm{dS} \mathrm{m}^{-1}$ salinity level.

Seedling Root Dry Weight (RDW): The two ways ANOVA for accessions and treatment*accession interaction was found statistically insignificant ( $p>0.05$ ). However, it was significant $(\mathrm{p}<0.05)$ for treatments. As compared to the control, seedling Root Dry Weight (RDW) was enhanced at $2 \mathrm{dS} \mathrm{m}^{-1}$ in accessions 223247 and 69239. It was reduced in all accessions at 4 and $8 \mathrm{dS} \mathrm{m}^{-1}$ but more profoundly at the latter salt concentration. At $8 \mathrm{dS} / \mathrm{m}$, accessions 237267,237265 , $228851,223247,237311$ and 69309 were more salt-affected however, accessions 239211, 239237, 237266, 223550, $234093,235461,69239$ and 69029 were least salt-affected in comparison with the control (Fig. 2).

Seedling Shoots Relative Water Content (SRWC): The two ways ANOVA showed statistical significance for treatment $(\mathrm{p}<0.001)$ and accessions $(\mathrm{p}<0.01)$ with respect to seedling Shoot Relative Water Content (SRWC). However, it was significant for accession*treatment interaction ( $>0.05)$. Seedling Shoot Relative Water Content (SRWC) was facilitated in accessions 237311, $237267,237266,228851,223247,235461,237264$ and 69309 at $2 \mathrm{dS} \mathrm{m}^{-1}$ as compared to the control. Moreover, it was facilitated both at 2 and $4 \mathrm{dS} \mathrm{m}^{-1}$ in accessions 237265 and 69239. Accessions 239211, 69096, 223247, 69117, 237264 and 237267 had the lowest SRWC and but accessions 237311, 237265, 228851, 223550, 69309 and 69029 possessed the highest Shoot Relative Water Content (SRWC) compared to other accessions (Fig. 3).

Seedling Roots Relative Water Content (RRWC): The two ways ANOVA for treatments was statistically significant $(\mathrm{p}<0.05)$ but insignificant for accessions and treatment*accession interaction ( $\mathrm{p}>0.05$ ) with respect to seedling Root Relative Water Content (RRWC). There was no significant variation among accessions in their RRWC except in accessions 237311, 237267, 237265, 234071,231190 and 234093 its value being a bit higher than the rest accessions (Fig. 4).

Inaccessions 239211, 237266, 223247, 234071, 231190, 237264, 69117 and 69096 Shoot Fresh Weight (SFW) decreased as the salinity level increased. This does agree 
Res. J. Agron., 4 (2): 24-30, 2010

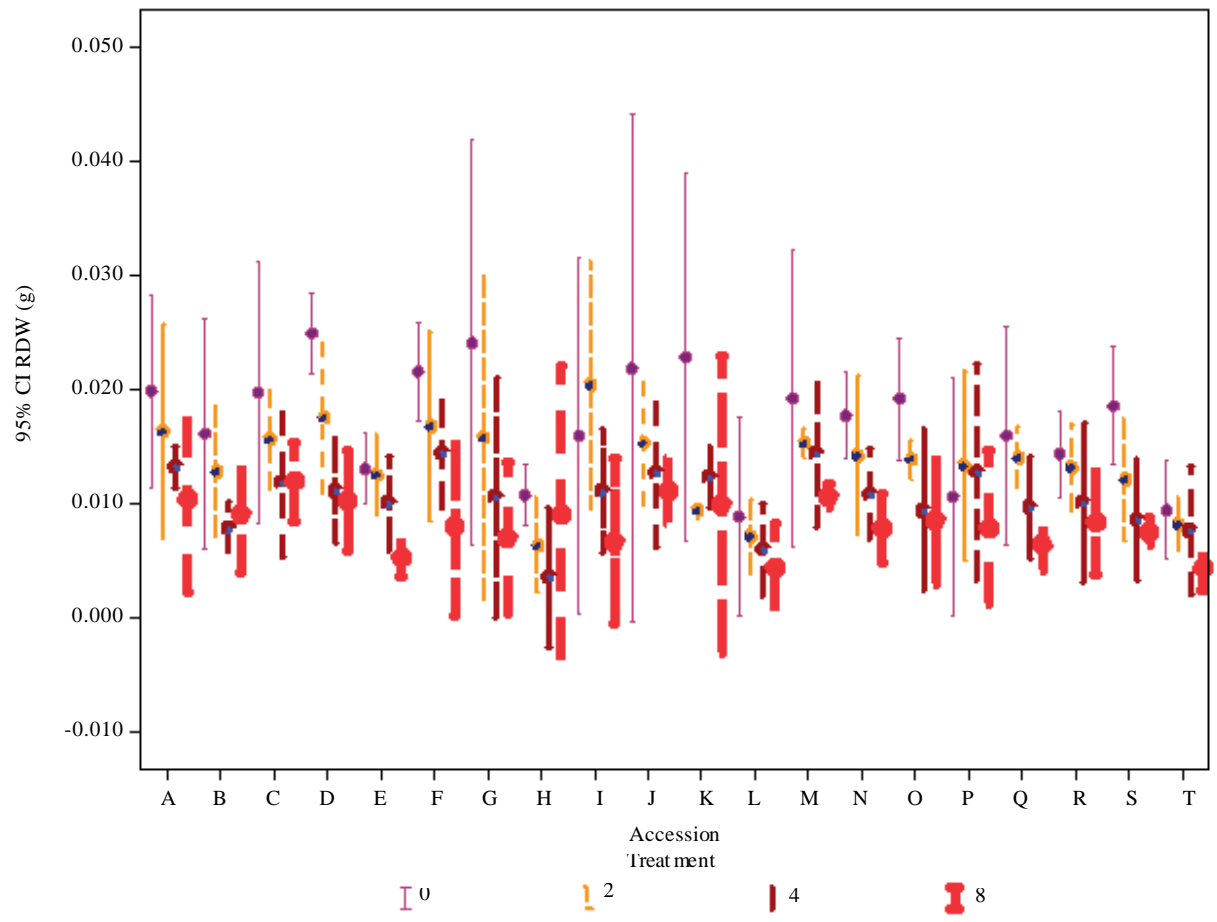

Fig. 2: Effects of different salinity levels $\left(0,2,4\right.$ and $\left.8 \mathrm{dS} \mathrm{m}^{-1}\right)$ on seedling Root Dry Weight (RDW) of Sorghum bicolor L. Moench accessions $(\mathrm{g})(\mathrm{A}=237311, \mathrm{~B}=239211, \mathrm{C}=239237, \mathrm{D}=237267, \mathrm{E}=237266, \mathrm{~F}=237265, \mathrm{G}=228851$, $\mathrm{H}=223550, \mathrm{I}=223247, \mathrm{~J}=234071, \mathrm{~K}=231190, \mathrm{~L}=234093, \mathrm{M}=235461, \mathrm{~N}=237264, \mathrm{O}=69117, \mathrm{P}=69239, \mathrm{Q}=$ 69309, $\mathrm{R}=69096, \mathrm{~S}=69086$ and $\mathrm{T}=69029$ )

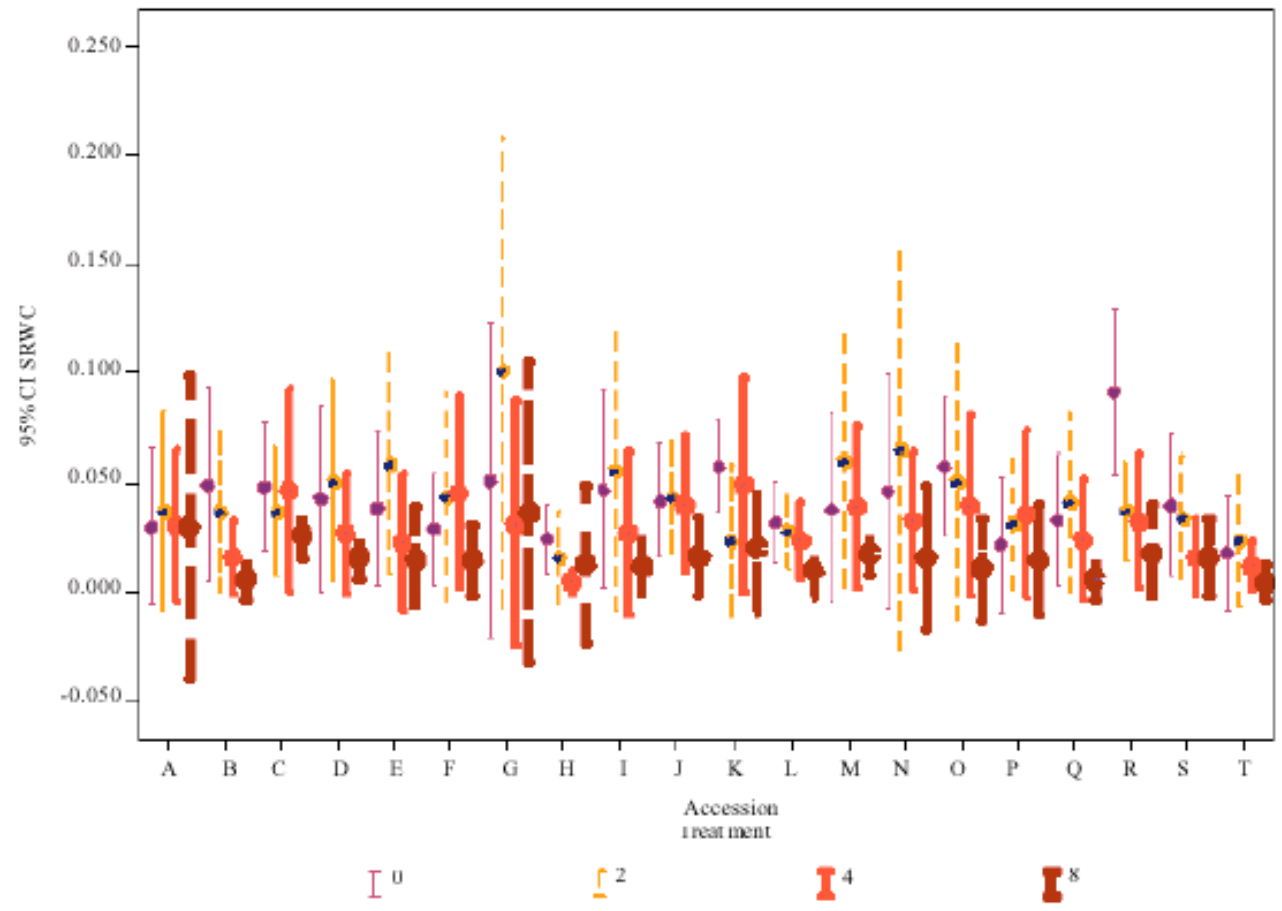

Fig. 3: Effects of different salinity levels $\left(0,2,4\right.$ and $\left.8 \mathrm{dS} \mathrm{m}^{-1}\right)$ on the seedling Shoot Relative Water Content (SRWC) of Sorghum bicolor L. Moench accessions $(\mathrm{A}=237311, \mathrm{~B}=239211, \mathrm{C}=239237, \mathrm{D}=237267, \mathrm{E}=237266, \mathrm{~F}=$ $237265, \mathrm{G}=228851, \mathrm{H}=223550, \mathrm{I}=223247, \mathrm{~J}=234071, \mathrm{~K}=231190, \mathrm{~L}=234093, \mathrm{M}=235461, \mathrm{~N}=237264, \mathrm{O}=69117$, $\mathrm{P}=69239, \mathrm{Q}=69309, \mathrm{R}=69096, \mathrm{~S}=69086$ and $\mathrm{T}=69029)$ 


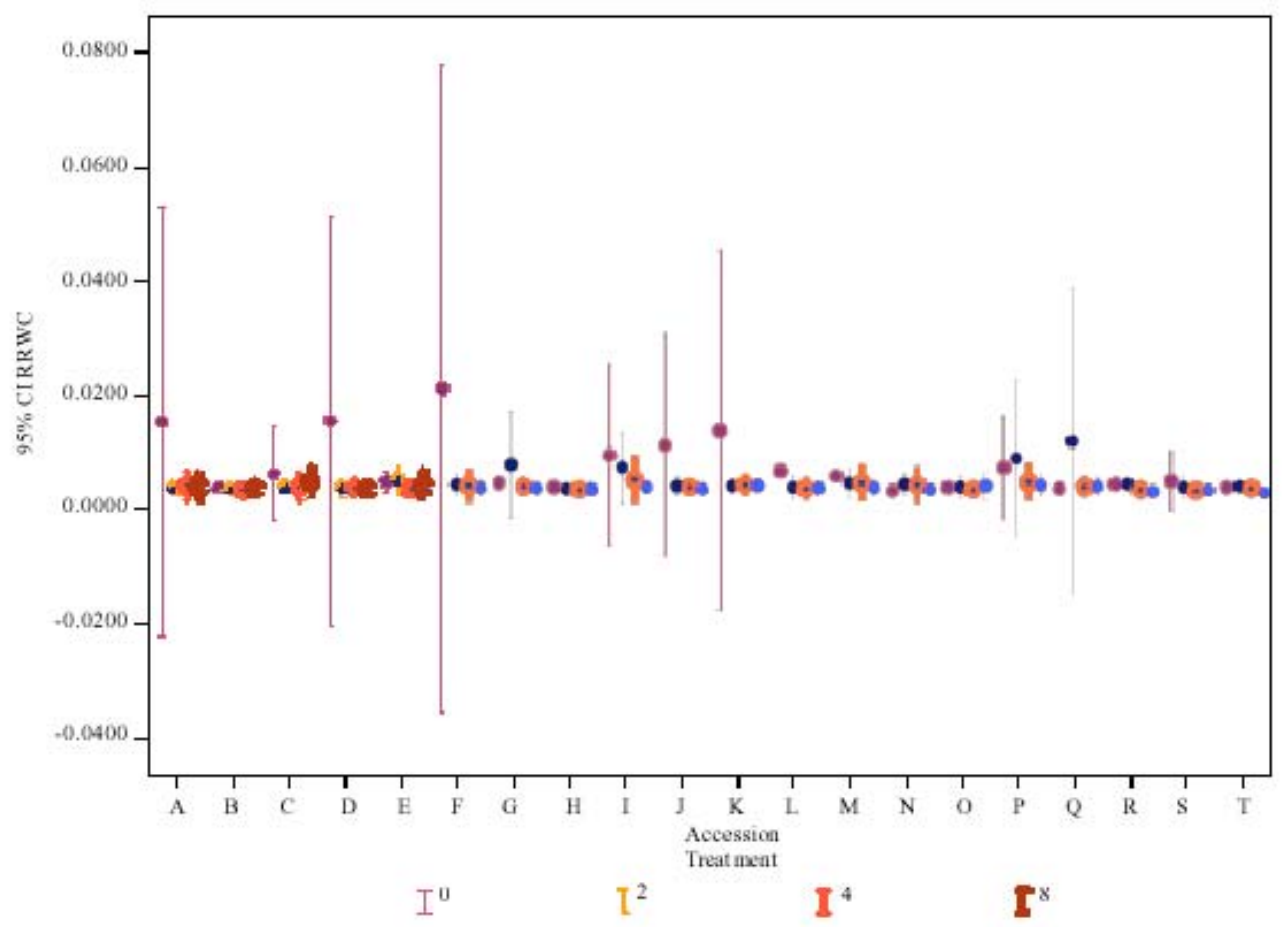

Fig. 4: Effects of different salinity levels $\left(0,2,4\right.$ and $\left.8 \mathrm{dS} \mathrm{m}^{-1}\right)$ on the seedling Root Relative Water Content (RRWC) of Sorghum bicolor $\mathrm{L}$. Moench accessions $(\mathrm{A}=237311, \mathrm{~B}=239211, \mathrm{C}=239237, \mathrm{D}=237267, \mathrm{E}=237266, \mathrm{~F}=$ $237265, \mathrm{G}=228851, \mathrm{H}=223550, \mathrm{I}=223247, \mathrm{~J}=234071, \mathrm{~K}=231190, \mathrm{~L}=234093, \mathrm{M}=235461, \mathrm{~N}=237264, \mathrm{O}=69117$, $\mathrm{P}=69239, \mathrm{Q}=69309, \mathrm{R}=69096, \mathrm{~S}=69086$ and $\mathrm{T}=69029)$

with previous studies conducted in durum wheat and tef (Mamo et al., 1996) and phaseolus species (Bayuelo-Jimenez et al., 2002).

Increased salinity level caused simultaneous reduction of seedling shoots and roots fresh weights in accessions 237267 and 223247. This is in line with previous reports in wheat (Afzal et al., 2005) and sugar beat, cabbage, amaranth and pak-choi (Jamil and Lee, 2006). In general, seedling Shoot Fresh Weight (SFW) was more salt-affected than seedling Root Fresh Weight (RFW). This is in accord with previous research reports in wheat and triticale genotypes (Shalaby et al., 1993), Phaseolus species (Bayuelo-Jimenez et al., 2002) and sugar beat, cabbage, amaranth and pak-choi (Jamil and Lee, 2006).

Increased salinity level caused simultaneous reduction in seedling root and shoot dry matter production (SDW and RDW) in accessions 237267 , 237265,228851 and 223247. Similar research results were reported in sorghum (Boursier and Lauchli, 1990), wheat and triticale genotypes (Shalaby et al., 1993), barely (Cho and Kim, 1998) and Prosopis alba (Meloni et al., 2004). On the other hand, both seedling fresh and dry biomass production (SFW, RFW, SDW and RDW) were concurrently reduced as a result of increased salinity level in accessions $237267,237265,228851$ and 223247 . This does agree with previous research findings in rice (Shannon et al., 1998), Phaseolus species (Bayuelo-Jimenez et al., 2002), wheat (Afzal et al., 2005) and catharanthus roseus (Jaleel et al., 2008).

Seedling Relative Water Content (RWC) was drastically decreased at higher salinity level, $8 \mathrm{dS} \mathrm{m}^{-1}$. However, the impact was remarkable on Shoot Relative Water content (SRRW) compared to the Root Relative Water Content (RRWC). This is in agreement with previous reports in lentil (Ashraf and Waheed, 1993), Maize (Cicek and Cakirlar, 2002), Prosopis alba (Meloni et al., 2004). Salinity stress had no significant effect on seedling shoot and root Relative Water Content (RWC) in accessions 237311, 239237, 228851, 223550, $69239,69029,237266$ and 235461. Similar result was reported in lentil (Ashraf and Waheed, 1993).

The two ways ANOVA for treatments was significant with regard to all parameters considered. On the one hand, the ANOVA for accessions was insignificant with respect to SFW, SDW, RDW, RRWC and SRWC. This implies that there were no significant varietal differences among sorghum accessions in relation to the parameters considered. However, it was significant with respect to RFW. This reveals the presence of considerable varietal 
differences among sorghum accessions in respect of RFW. Accession*treatment interaction was insignificant for seedling Shoot Fresh Weight (SFW), seedling Root Fresh Weight (RFW), seedling Shoot Dry Weight (SDW) and seedling Root Dry Weight (RDW) reflecting that all accessions responded similarly to salt stress with respect to these parameters. In general, salt stress at $2 \mathrm{dS} \mathrm{m}^{-1}$ has enhanced growth with respect to SFW, RFW, SDW, RDW, RRWC and SRWC in some accessions. The impact of 2 and $4 \mathrm{dS} \mathrm{m}^{-1}$ salinity levels was not profound with respect to all parameters considered. Nevertheless, all accessions were quite salt-sensitive at $16 \mathrm{dS} \mathrm{m}^{-1}$ with regard to SFW, RFW, SDW and RDW.

\section{CONCLUSION}

Crop cultivar may germinate effectively under salt stress; nevertheless, its seedling growth may be saltaffected (Azhar and McNeilly, 1987). In line with this, accessions 237311 and 234071 were less salt-affected during germination (Geressu and Gezahagne, 2008) than subsequent growth (had inadequate seedling biomass production and relative water content). This implies that these accessions are salt tolerant during germination than subsequent growth like seedling biomass production and relative water content. On the other hand, crop genotype may be salt sensitive during both germination and seedling growth. This has already been reported in rice (Shannon et al., 1998) and cowpea (Murillo-Amador and Troyo-Dieguez, 2000). Similarly, in this research accession 223247 found salt sensitive at higher salinity levels during germination and seedling biomass production and through its relative water content. Thus, this sorghum accession could not be directly cultivated even on slightly saline soils.

On the other hand, accessions 235461 and 69239 were found salt tolerant with respect to seedling biomass production and Relative Water Content (RWC). These accessions also had the lowest germination rate (rapid emergence), the highest Final Germination Percentage (FGP) and facilitated seedling growth in another study (Geressu and Gezahagne, 2008). Their salt tolerance capability might emanate from their faster germination which allowed the emerging seedlings to accumulate more biomass relative to the control (Bayuelo-Jimenez et al., 2002). Thus due to the facilitated seedling root and shoot characteristics these genotypes were enabled to possess the highest seedling Relative Water Content (RWC) which in turn enabled them to tolerate the toxic effects of salts through dilution (Lee and Senadhira, 1998). Since these two sorghum accessions had rapid emergence, highest Final Germination
Percentage (FGP), facilitated seedling growth, highest seedling biomass production and Relative Water Content (RWC) they could effectively establish themselves on moderately saline soils.

\section{ACKNOWLEDGEMENTS}

The researcher would like to express his heartfelt thanks to NORAD II Research Award for its financial assistance. Moreover, the researcher is greatly indebted to Mekelle University (MU), Department of Biology for providing the laboratory and also the Institute of Biodiversity Conservation (IBC) for supplying all the twenty sorghum (Sorghum bicolor Moench. L) accessions. Finally, great gratitude and thanks goes to Ato Hayal Lemma and Ato Getachew Gidey for their genuine technical support during the experiment.

\section{REFERENCES}

Abegaz, F., 1995. Effects of subsurface drainage system on ground water table, soil salinity and crop yield in Melka Sadi pilot draiange scheme. Proceedings of the First and Inaugural Conference of the Agronomy and Crop Physiology of Ethiopia, May 30-31, Addis Ababa, Ethiopia, pp: 139-148.

Afzal, I., S. Maqsood, A. Basra, N. Ahmad and M. Farooq, 2005. Optimization of hormonal priming techniques for alleviation of salinity stress in wheat (Triticum aestivum L.). Caderno Pesquisa serie Biologia, 17: 95-109.

Ashraf, M. and A.Waheed, 1993. Resposes of some local/exotic accessions of lentil (Lens culinaris Medic.) to salt stress. J. Agron. Crop Sci., 170: 103-112.

Ashraf, M. and T. McNeilly, 1988. Variability in salt tolerance of nine spring wheat cultivars. J. Agron. Crop Sci., 160: 14-21.

Azhar, M.F. and T. McNeilly, 1987. Variability for salt tolerance in Sorghumn bicolor (L.) Moench. under hydroponic conditions. J. Agro. Crop Sci., 159: $269-277$.

Bayuelo-Jimenez, J.S., R. Graig and J.P. Lynch, 2002. Salinity tolerance of Phaseolus species during germination and early seedling growth. Crop Sci., 42: 1584-1594.

Boursier, P. and A. Lauchli, 1990. Growth responses and mineral nutrient relations of salt-stressed sorghum. Crop Sci., 30: 1226-1233.

Brady, N.C. and R.R. Weil, 2002. The Nature and Properties of Soils. 13th Edn., Prentice Hall, New Jersey, ISBN: 0130167630. 
Cho, J.W. and C.S. Kim, 1998. Effect of $\mathrm{NaCl}$ concentration on photosynthesis and mineral content of barely seedlings under solution culture. Korean J. Crop Sci., 43: 152-156.

Cicek, N. and H. Cakirlar, 2002. The effect of salinity on some physiological parameters in two maize cultivars. BULG. J. Plant Physiol., 28: 66-74.

El-Khashab, A.A.M., A.A. Elaidy, A.F. El-Sammak, M.I. Salama and M. Rienger, 1997. Paclobutrazol reduces some negative effects of salt stress in peach. J. Am. Soc. Hort. Sci., 122: 43-46.

FAO, 2005. Global Network on Integrated Soil Management for Sustainable Use of Salt-Affected Soils. FAO, Land and Plant Nutrition Management Service, Rome, Italy.

Gebreselassie, T., 1993. Degradation problems of irrigated agriculture: A review. Proceedings of the Second Conference of ESSS, Sept. 23-24, Addis Ababa, Ethiopia, pp: 199-206.

Geressu, K. and M. Gezahagne, 2008. Response of some lowland growing sorghum (Sorghum bicolor L. Moench) accessions to salt stress during germination and seedling growth. Afr. J. Agric. Resour., 3: 44-48.

Gupta, R. and P.S. Minhas, 1993. Managing Salt Affected Waters for Crop Production. In: Arid Land Irrigation and Ecological Management, Singh, S.D. (Ed.). Scientific Publishers, Jodhpur New Delhi, India, pp: 159-198.

Jaleel, C.A., B. Sankar, R. Sridharan and R. Panneerselvam, 2008. Soil salinity alters growth, chlorophyll content and secondary metabolite accumulation in Catharanthus roseus. Turk. J. Biol., 32: 79-83.

Jamil, M. and D. Lee, 2006. Effect of salt ( $\mathrm{NaCl}$ ) stress on germination and early seedling growth of four vegetables species. Central Eur. Agric. J., 7: 273-283.

Katerji, N., J.W. Von Hoorn, A. Hamdy, F. Karam and M. Mastrorilli, 1994. Effect of salinity on emergence and on water stress and early seedling growth of sunflower and maize. Agric. Water Manage., 26: 81-91.
Lee, S.Y. and D. Senadhira, 1998. Salinity tolerance of progenies between Korean cultivars and IRR's new plant type lines in rice. Korena J. Crop Sci., 43: 234-238.

Maas, E.V., 1986. Salt tolerance of plants. Applied Agric. Res., 1: 12-26.

Mamo, T., C. Richter and B. Heiligatag, 1996. Response of some varieties of durum wheat and tef to salt stress. J. Afr. Crop Sci., 4: 423-432.

Marambe, B. and T. Ando, 1995. Physiological basis of salinity tolerance of sorghum seeds during germination. J. Agron. Crop. Sci., 174: 291-296.

Marler, T.E. and M.V. Mickelbart, 1993. Growth and chlorophyll fluorescence of Spondias purpurea L. as influenced by salinity. Tropical Agric., 70: 245-247.

Meloni, D.A., M.R. Gulotta, C.A. Martinez and M.A. Oliva, 2004. The effect of salt stress on growth, nitrate reduction and praline and glycinebetaine accumulation in prosopis alba. Braz. J. Plant Physiol., 16: 39-46.

Murillo-Amador, B. and E. Troyo-Dieguez, 2000. Effects of salinity on the germination and seedling characteristics of cowpea [Vigna unguiculata (L.) Walp.]. Aust. J. Exp. Agric., 40: 433-438.

Shalaby, E.E., E. Epstein and C.O. Qualset, 1993. Variation in salt tolerance among some wheat and triticale genotypes. J. Agron. Crop Sci., 171: 298-304.

Shannon, M.C., J.D. Rhoades, J.H. Draper, S.C. Scardaci and M.D. Spyres, 1998. Assessment of salt tolerance in rice cultivars in response to salinity problems in California. Crop Sci., 38: 394-398.

Tsige, H., T. Gebresellasie and T. Mamo, 2000. Assessment of salinity/sodicity problems in Abaya State Farm, Southern Rift Valley of Ethiopia. Ethiopian J. Nat. Resour., 2: 151-163.

Verma, S.P.O. and R.B.R. Yadava, 1986. Salt tolerance of some oats (Avena sativa L.) varieties at germination and seedling stage. J. Agron. Crop Sci., 156: 123-127. 